\title{
Residential Utility Management
}

\author{
Angela Liu
}

\begin{abstract}
The price of residential electricity is soaring. We must find an effective way to cut down the energy usage. I developed an effective procedure to measure the real-time power usage pattern and the annual utility cost to charge my electronic gadgets. After understanding the electric usage pattern, I developed actionable energy-saving steps to lower my household electricity consumption and utility bills. This project was based on a real-life experiment; not on the wattage or electricity usage specifications from device manufactures' catalog. We found that most manufactory electrical usage specifications are over-optimistic and very conservative. For example, HP claimed that their LaserJet Pro 400 M401dn only use 570 watts while printing; actually it used $30 \%$ more, i.e., 750 watts. By changing our family behaviors and life style, we can reduce our electric consumption up to $40 \%$, i.e. over $\$ 1,200$, per year.
\end{abstract}

Index Terms-Measure utility, utility management, utility saving.

\section{INTRODUCTION}

The price of residential electricity is soaring. Electric bills have skyrocketed in the last several years [1], [2]. US Department of Energy projected that the price of one kilowatt-hour of electricity (in nominal dollars) would increase about five times from $\$ 0.08 / \mathrm{kWh}$ in 1996 to $\$ 0.39 / \mathrm{kWh}$ in 2034 Fig. 1. We have to cut down the energy consumption.

\section{Price of Residential Electricity}

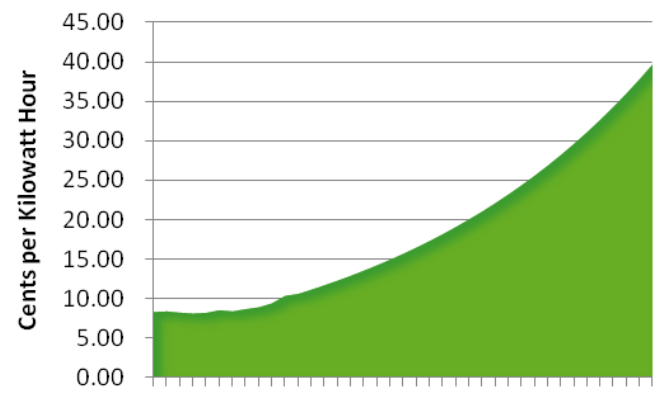

19962001200620112016202120262031

Fig. 1. DOE projected that the price of kilowatt-hour is soaring.

Current utility monthly bill offers us no information on the energy consumption of individual appliance. It makes us very difficult to figure out how to reduce the household energy consumption effectively.

We need real-time and accurate energy consumption and utility cost of each individual appliance. Then, we would be more inspired to limit our energy use and to make better decisions about our energy use [3], [4]. In this project, I successfully addressed the following questions:

Manuscript received October 25, 2013; revised January 22, 2014

Angela Liu is with Polytechnic School, Pasadena, CA 91106 USA (e-mail: Angela.ch.liu@gmail.com).
1) What is the annual utility cost of each of my electronic devices and gadget?

2) How much electric power they consume?

3) What are their power usages vs. time?

4) How efficient they really are?

5) How can I reduce the utility cost by changing our behavior?

\section{PROCEDURE}

I purchased three "Kill A Watt EZ Electricity Usage Monitors" to help me measure the real-time power usage over time of each electronic gadget [5]-[8]. Knowledge is power. The EZ monitor calculated the projected annual utility cost of each appliance.

I plugged an electrical appliance into EZ monitor, and plug EZ monitor into a wall outlet. EZ sits between the appliance plug and the electric socket. As electricity moved through the monitor and into the appliance, the device tracked and recorded how much electricity the appliance was drawing to operate. The EZ displayed the power usage over time in watt, power consumption in Kilowatt-hours (kWh), and the running cost of my family's electrical expenses by the day, week, month or year.

\section{REAL-TIME POWER USAGE OF ELECTRONIC GADGETS}

I measured the electrical usage over time of using Sony VAIO desktop all-in-one PC Fig. 2.

1) VAIO used up to 96 Watt in the first 6 seconds of booting (transient state) and dropped to steady state of 60 Watt at about the 50-second mark. The entire booting process is about two and half minutes.

2) Playing the BluRay DVD required about 35 Watts. The EZ monitor indicated the power increased from 60 Watts to 95 Watts.

3) Viewing YouTube video added additional 5 to 10 Watts.

4) Turning off the monitor, the electricity usage dropped 25 watts, from 65 watts to 40 watts.

5) Shutting down the VAIO increased the usage from 60 Watts to 83 Watts for the first 20 seconds, before it was completely shut down. VAIO experienced another transient state.

I also measured the electrical usages of other gadgets and compared them with Sony VIAO Fig. 3:

1) Sony VAIO desktop all-in-one: $\sim 68$ watts

2) Lenovo ThinkPad Laptop T510: 60 watts

3) Apple MacBook Pro 15" Retina Display: 12 watts

4) HP PhotoSmart Premier Color Printer: $\sim 6$ Watts

5) HP LaserJet Pro 400 Printer M401dn: $\sim 6$ Watts. It used 750 watts to print one page.

6) iPAD: $\sim 6$ Watts

7) Canon VIXIA HF M30 HD camcorder: 2.3 Watts 
8) Cannon PowerShot ELPH 115 IS Camera: 1.2 Watts

9) iPhone 4S: $\sim 0.3$ Watts
Based on Fig. 3, I concluded that Apple gadgets are much more efficent than PCs.

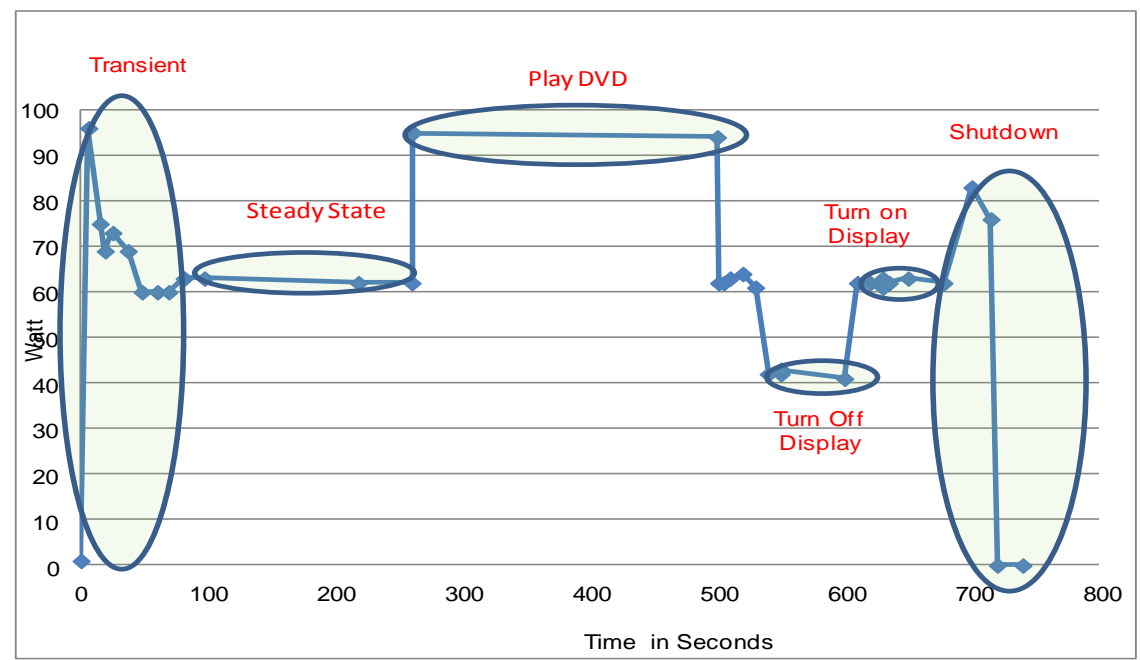

Fig. 2. Real-time electrical usage over time of using Sony VAIO desktop all-in-one.

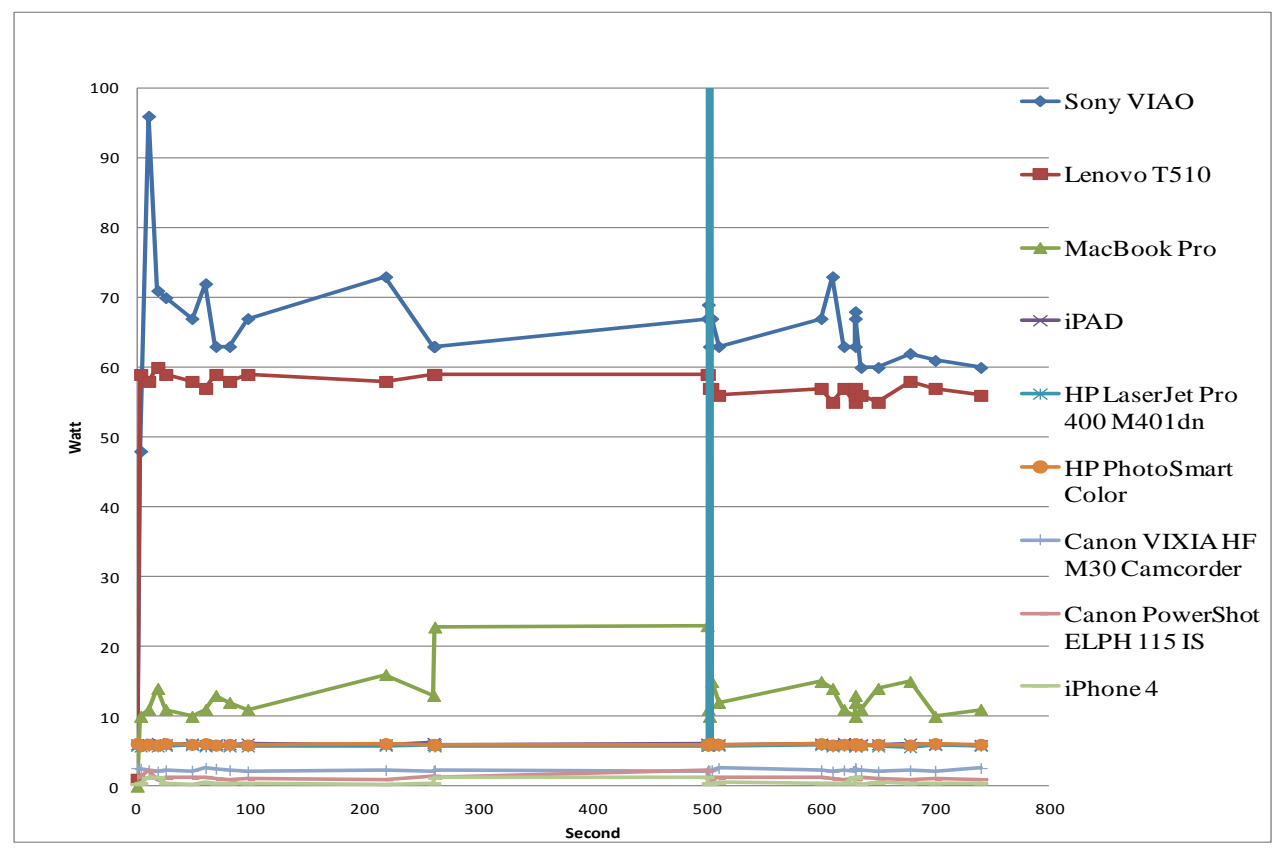

Fig. 3. Real-time power usage over time of my electronic gadgets.

\section{ENERGY CONSUMPTION OF ELECTRONIC GADGETS}

I connected each electronic gadget to the "Kill A Watt EZ Electricity Usage Monitor" for 24 hours. I then recorded the utility usage in $\mathrm{kWh}$ and the utility cost. All measurements were subject to uncertainty. I repeated each experience three times and took the average results. The average provided an estimate of the true value of the quantity that generally would be more reliable than an individual measured value. I also calculated the "standard deviation" of each set of measurements. Standard deviation showed how much variation or 'dispersion' there is from the 'average' mean value. The standard deviation of data set was the square root of its variance.

For example, we measured the kWh of 24-hr usage of Sony VAIO desktop all-in-one:

$$
P_{1}=0.89 \mathrm{kWh}, P_{2}=0.93 \mathrm{kWh} \text {, and } P_{3}=0.81 \mathrm{kWh} \text {. }
$$

The average power $P_{A}$ was

$$
\frac{P_{1}+P_{2}+P_{3}}{3}
$$

$\frac{(0.89 k W h+0.93 k W h+0.81 k W h)}{3}=0.88 \mathrm{kWh}$.

The standard deviation was

$$
\sqrt[2]{\frac{1}{3}\left[\left(P_{1}-P_{A}\right)^{2}+\left(P_{2}-P_{A}\right)^{2}+\left(P_{3}-P_{A}\right)^{2}\right]}
$$

$\sqrt[2]{\frac{1}{3}\left[(0.89 \mathrm{kWh}-0.88 \mathrm{kWh})^{2}+(0.93 \mathrm{kWh}-0.88 \mathrm{kWh})^{2}+(0.81 \mathrm{kWh}-0.88 \mathrm{kWh})^{2}\right]}$ $=0.09 \mathrm{kWh}$.

Therefore, the typical daily power consumption of VAIO desktop all-in-one was $(0.88 \pm 0.09) \mathrm{kWh}$. 
I measured each appliance for 24 hours three times and obtained the Typical Electricity Consumption (TEC):

1) Sony VAIO desktop all-in-one: $321 \pm 33 \mathrm{kWh} / \mathrm{yr}$

2) Lenovo ThinkPad Laptop T510: $261 \pm 25 \mathrm{kWh} / \mathrm{yr}$

3) HP LaserJet Pro 400 Printer M401dn: $111 \pm 12 \mathrm{kWh} / \mathrm{yr}$

4) HP PhotoSmart Premier Color Printer: $95 \pm 10 \mathrm{kWh} / \mathrm{yr}$

5) Apple MacBook Pro 15" Retina Display: $44 \pm 2 \mathrm{kWh} / \mathrm{yr}$

6) iPAD: $27 \pm 1 \mathrm{kWh} / \mathrm{yr}$

7) iPhone $4 \mathrm{~S}: 18 \pm 1 \mathrm{kWh}$

8) Cannon PowerShot ELPH 115 IS Camera: 14 $\pm 1 \mathrm{kWh}$

9) Canon VIXIA HF M30 HD camcorder: $17 \pm 2 \mathrm{kWh}$

Electricity bill is directly depending on how much power you use. By multiplying Southern California Edison rate per $\mathrm{kWh}$ with the utility usage of each household appliance, we got the monthly cost of each appliance.

Southern California Edison (SCE) bills us in four major categories:

1) Delivery charge: $\$ 0.12385$ per $\mathrm{kWh}$ (Average of Tier 1 , Tier 2, and Tier 3)

2) Generation Charge: $\$ 0.08469$ per $\mathrm{kWh}$

3) City Tax: $\$ 0.00914$ per $\mathrm{kWh}$

4) State Tax: $\$ 0.00029$ per kWh

In total, SCE charged us $\$ 0.19277$ per $\mathrm{kWh}$.

We can use this formula to figure the annual cost:

$(\mathrm{kWh}$ per year $) \times($ Cost per $\mathrm{kWh})=$ Cost of electricity per year

1) Sony VAIO desktop all-in-one: $\$(61.6 \pm 6.3) / \mathrm{yr}$

2) Lenovo ThinkPad Laptop T510: $\$(50.33 \pm 4.8) / \mathrm{yr}$

3) HP LaserJet Pro 400 Printer M401dn: $\$(21.42 \pm 2.5) / \mathrm{yr}$

4) HP PhotoSmart Premier Color Printer: $95 \pm 10 \mathrm{kWh} / \mathrm{yr}$

5) Apple MacBook Pro 15" Retina Display: $\$(8.59 \pm 4) / \mathrm{yr}$

6) iPAD: $\$(5.26 \pm 2) / \mathrm{yr}$

7) iPhone $4 \mathrm{~S}: \$(3.37 \pm 1) / \mathrm{yr}$

8) Canon VIXIA HF M30 HD camcorder: $\$(3.5 \pm 4) / \mathrm{yr}$

9) Cannon PowerShot ELPH 115 IS Camera: $\$(2.8 \pm 0.1) / y r$

In total, I need to pay $\$(150.67 \pm 14)$ each year to charge all my electronic gadgets, as in Fig. 4.

Those electronic gadgets continue to draw a small amount of stand-by electricity when they are switched "off." Those appliances use electricity to display clocks or maintain schedule. This type of "phantom energy" use can add up and can be avoided by unplugging the gadgets or using a power strip and using the switch on the power strip to cut all power to the appliance. Based on my measurements, I can save about $390 \mathrm{kWh}$ or $\$ 75$ per year, which would be half of the total gadget utility cost, as in Fig. 4.

1) Sony VAIO desktop all-in-one: $\$ 27.31 / \mathrm{yr}$

2) Lenovo ThinkPad Laptop T510: $\$ 28.92 / \mathrm{yr}$

3) HP LaserJet Pro 400 Printer M401dn: $\$ 11.78 / \mathrm{yr}$

4) HP PhotoSmart Premier Color Printer: $95 \pm 10 \mathrm{kWh} / \mathrm{yr}$

5) Apple MacBook Pro 15" Retina Display: $\$ 3.96 / \mathrm{yr}$

6) iPAD: $\$ 2.25 / \mathrm{yr}$

7) iPhone 4S: $\$ 1.39 / \mathrm{yr}$

8) Canon VIXIA HF M30 HD camcorder: $\$(3.5 \pm 4) / \mathrm{yr}$

9) Cannon PowerShot ELPH 115 IS Camera: $\$ 0.86 / \mathrm{yr}$

\section{ENERGY CONSUMPTION AND ELECTRIC COST OF MAJOR APPLIANCES}

The maximum voltage for The "Kill A Watt EZ Monitor" is 125 volts and the maximum current is 15 amps [9]. The maximum power it can handle is 1,875 Watt [10], [11]. I used three "Kill A Watt EZ Electricity Usage Monitors" to help me monitor the power usage (in watt), energy consumption (in $\mathrm{kWh}$ ), and the utility cost (in dollar) of some smaller appliance.

Some other major appliances, such as central air conditioner, clothes dryer, and range with oven, which had bigger voltage and current load than the Kill a Watt can handle. Several other appliances that could not be measured by the Kill a Watt meter, such as ceiling lights which did not have a wall plug for us to plug in Kill A Watt Monitor.

SCE utility watt-hour meter helped me to determine the energy consumption of those major appliances. I turned off all of the other appliances in my house prior to measurement. This way I knew that all of the power was consumed by the appliance I am measuring.

We measured each appliance three times to ensure that my results are valid.

1) Central Air Conditioner $(60,000$ BTU/Hour $)$ : $(8520 \pm 1123) \mathrm{kWh}$

2) Refrigerator/Freezer (SubZero 48-in): $(1,402 \pm 178) \mathrm{kWh}$

3) Swimming Pool Pump (3/4 Horse Power): (1,305 \pm 120$)$ $\mathrm{kWh}$

4) Computers, Printers, Routers: $(781 \pm 97) \mathrm{kWh}$

5) Cloth Dryer: $(769 \pm 94) \mathrm{kWh}$

6) Lighting: $(723 \pm 93) \mathrm{kWh}$

7) Range with Oven: $(701 \pm 89) \mathrm{kWh}$

8) Dish Washer: $31.12 \mathrm{kWh}$

9) Sprinkler System: $28.97 \mathrm{kWh}$

10) Television: $27.11 \mathrm{kWh}$

11) Hair Dryer: $26.21 \mathrm{kWh}$

12) Ceiling Fan: $12.31 \mathrm{kWh}$

13) Washing Machine: $11.04 \mathrm{kWh}$

14) Cloth Iron: $10.12 \mathrm{kWh}$

15) Toaster: $5 \mathrm{kWh}$

16) iPad \& iPhone: $3.12 \mathrm{kWh}$

Electricity bills vary directly depending on how much power you use. By multiplying Southern California Edison rate per $\mathrm{kWh}$ with the utility usage of each major household appliance, we can calculate the monthly cost of each appliance Fig. 5.

1) Central Air Conditioner: $\$ 136.32$

2) Refrigerator/Freezer (SubZero 48-in): $\$ 22.43$

3) Swimming Pool Pump (3/4 Horse Power): $\$ 21.5$

4) Computers, Printers, Routers: $\$ 12.4$

5) Cloth Dryer: $\$ 12.31$

6) Lighting: $\$ 11.56$

7) Range with Oven: $\$ 11.22$

8) Dish Washer: $\$ 5.98$

9) Sprinkler System: $\$ 5.57$

10) Television: $\$ 5.21$

11) Hair Dryer: $\$ 5.84$

12) Ceiling Fan: $\$ 2.37$

13) Washing Machine: $\$ 2.12$

14) Cloth Iron: $\$ 1.95$

15) Toaster: $\$ 0.96$

16) iPad \& iPhone: $\$ 0.61$

On average, my home pays $55 \%$ for heating and air-conditioning systems; $10 \%$ for our subzero refrigerator/freezer, $5 \%$ for swimming pool pump, cloth 
dryer, lighting, and range/oven each. Those six items consume about $85 \%$ of the utility bill.

I also recorded the wattage of each household appliance in Fig. 6. Air conditioning units, clothes dryer, rage oven, dish washer, hair dryer, swimming pool pump, and toaster were electricity hogs in my family. They all had insatiable appetites for electricity and using them too often can drive your electricity bill way up.

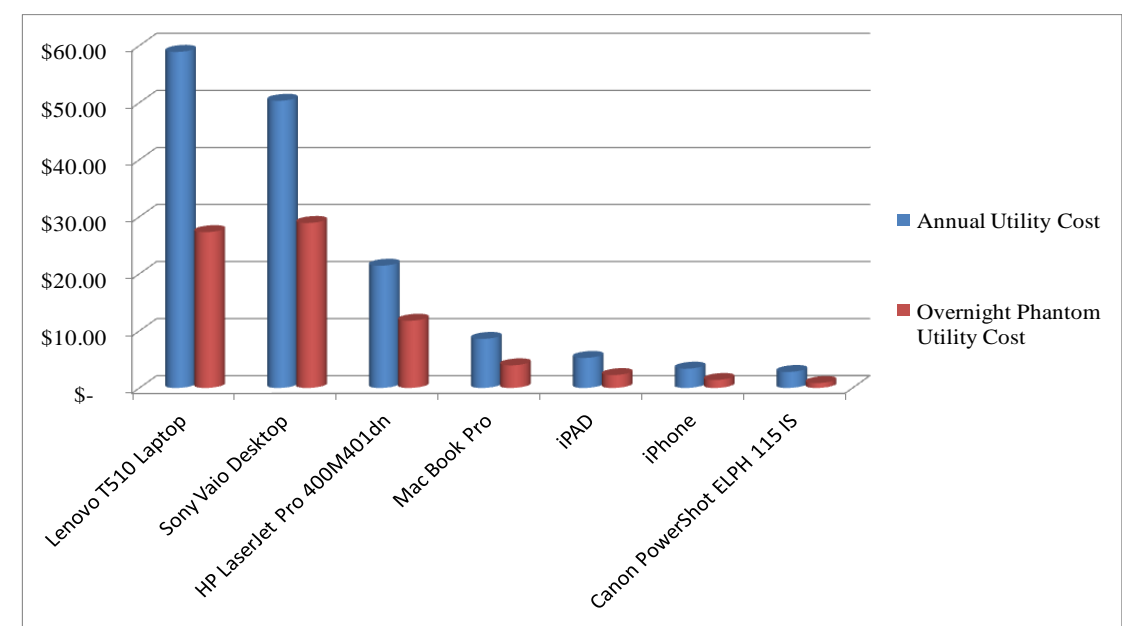

Fig. 4. Annual electric cost of using my electronic gadgets.

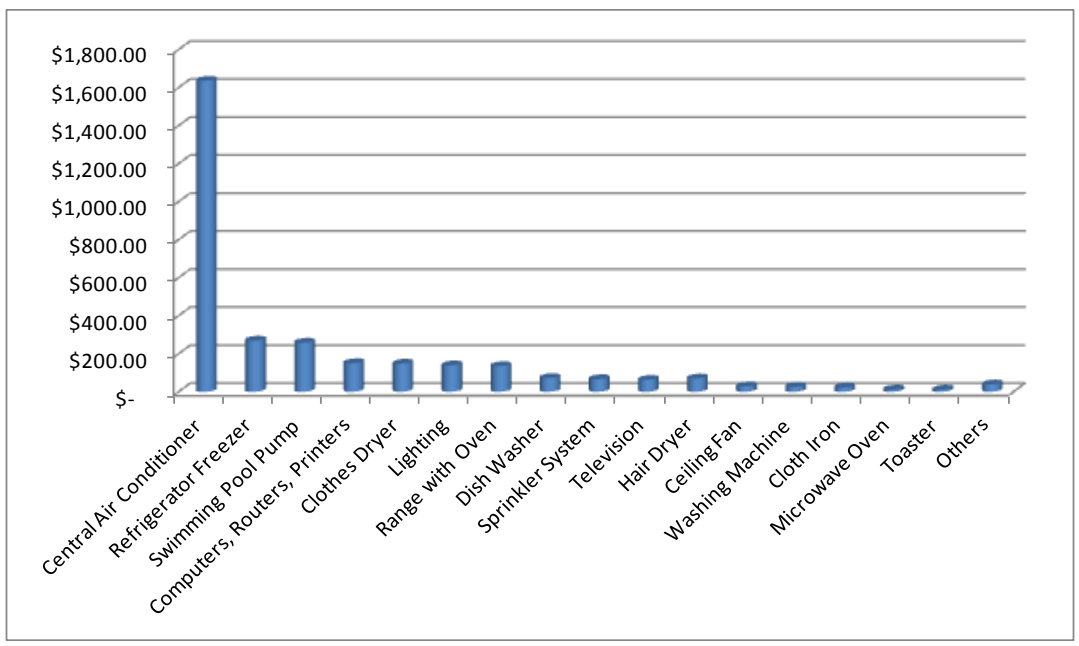

Fig. 5. Monthly appliance utility cost of major appliances.

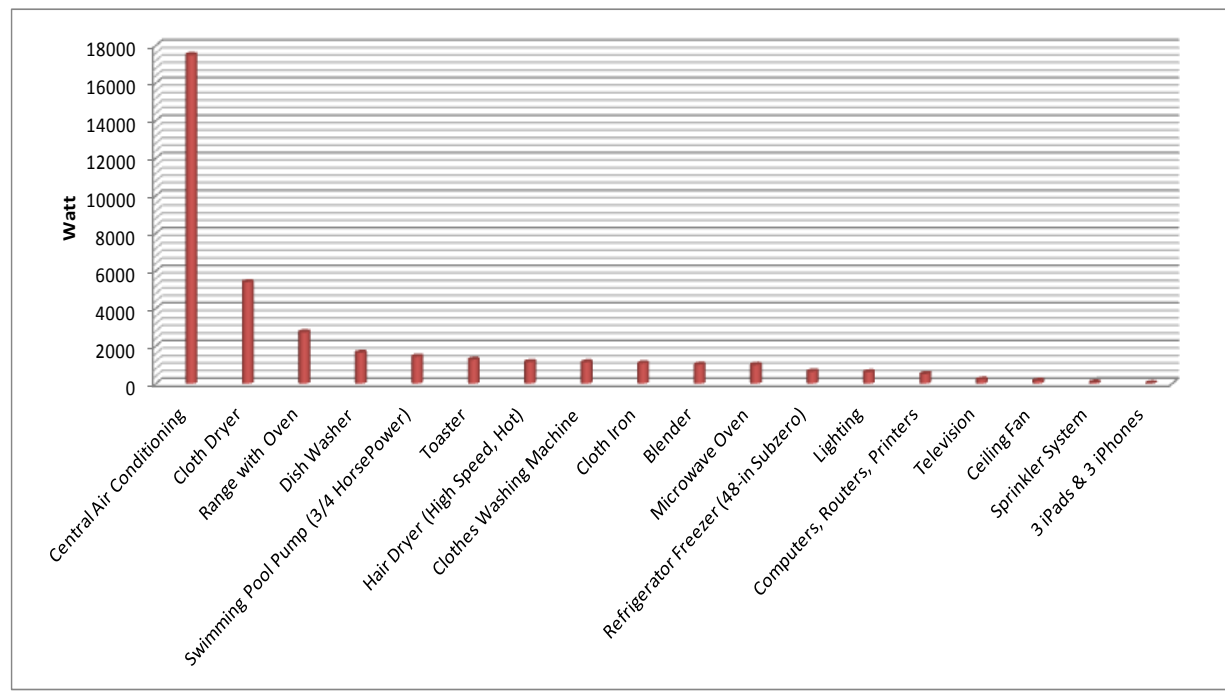

Fig. 6. Power usage of my home appliances.

\section{SAVE ELECTRICITY}

To lower the utility bills effectively, we should focus on the top electricity hogs appliances:

\section{A. Central Air Conditioning}

1) Set our home thermostat between 78 and 80 degrees in summer.

2) Clean or replace our air conditioner filters frequently. 
3) Install attic exhaust fans to remove hot air from attic space.

4) Whether relying on natural ventilation or forcing air through your home with fans, ventilation is the most energy-efficient way to cool your house. To run a fan is 100 times cheaper than to run a 5-ton air condition unit. The power usage for a fan is 155 watt; on the other hand, the air conditioner requires 17,500 watt.

\section{B. Refrigerator/Freezer}

Set the refrigerator temperature between $36^{\circ} \mathrm{F}$ and $42^{\circ} \mathrm{F}$. Set the freezer control so the temperature is between $-5^{\circ} \mathrm{F}$ and $+6^{\circ} \mathrm{F}$. Don't set the temperature colder than necessary. A small thermometer placed in the refrigerator or freezer help my family to set it correctly.

\section{Swimming Pool Pump}

Don't use pump past its prime time. Old pump simply uses more energy and less efficient. A new energy-efficient pump uses about four times less electricity than an older pump.

\section{Computers, Routers, and Printers}

1) Eliminate "phantom loads". It saves us more than 400 $\mathrm{kWh}$ or $\$ 75$ per year by using the switch on the power strip to cut all power to the electronic gadgets over night.

2) Install screen saver: Screen saver reduced 25 watt on either my Sony VAIO desktop all-in-one or my Lenovo ThinkPad Laptop T510.

3) Reduce unnecessary print: HP LaserJet Pro 400 Printer M401dn used 750 watt to print!

4) Use more Mac than PCs: MacBook used much less electricity than PCs. MacBook Pro used about only $10 \%$ to $17 \%$ of my PC desktop or PC Laptop.

\section{E. Cloth Dryer}

Line drying our clothes. Clothes dryer is one of the highest electric usage devices in my home. It uses over 5,200 watt. We starts to dry our clothes on the clothes line.

\section{F. Lighting}

Lighting makes up about 10 percent of home energy costs. We can save 75 percent of that energy by replacing incandescent bulbs with compact fluorescent bulbs (CFLs). We should treat different types of light bulbs differently:

\section{G. Incandescent Lighting}

Incandescent lights should be turned off whenever they are not needed, because they are the least efficient type of lighting. Only $10 \%$ of the energy used for light and $90 \%$ of the energy they use is given off as heat. Turning lights off will also keep a room cooler, an extra benefit in the summer.

\section{H. Halogen Lighting}

While halogens are more efficient than traditional incandescent bulbs, they use the same technology and are far less efficient than CFLs and LEDs. Therefore, it is best to turn these lights off whenever they are not needed.

\section{CFL Lighting}

CFLs use a lot of energy to get started and it is better not to turn them off for short periods. If you will be out of a room for 15 minutes or less, leave it on. If you will be out of a room for more than 15 minutes, turn it off.

\section{J. LED Lighting}

The operating life of a light emitting diode (LED) is unaffected by turning it on and off. Turn off lights in unused rooms.

\section{CONCLUSION}

The cost of the electricity bill is soaring. "Kill A Watt" provided me with a real-time tool to monitor the electrical usages and energy consumptions of my household appliances. Knowledge is power. After understanding the electricity usage pattern, I developed effective ways to lower the electricity consumption and utility costs.

The approach used in this project encourages my involvement to use utility more effectively. Reducing significant monthly utility bill also provide all my family members with strong incentive to implement this approach.

By changing life style and behaviors, we can reduce our electric consumption by $40 \%$, i.e. over $\$ 1,200$, per year. We can also reduce greenhouse gases and air pollution.

This project was based on real-life measurements; not on the wattage or electricity usage specifications from device manufactures' catalog. I found that most manufactory electrical usage specifications were often over-optimistic and conservative.

\section{REFERENCES}

[1] U.S. Department of Energy, "DOE energy science and technology database," 2012

[2] U.S. Energy Information Administration, Short-Term Energy Outlook Supplement: Summer 2013 Outlook for Residential Electric Bills, 2013.

[3] International Energy Agency, "Energy efficiency market report", 2013.

[4] M. Enbysk, "Do you need to turn off your PC at night?" Microsoft Small Business Center, Retrieved June 12, 2008.

[5] Cut Your Electricity Costs With An Energy Monitor, The Greenest Dollar, March 2011.

[6] Energy Monitors, Consumer Reports, March 2009, Kill A Watt. P3, 2000.

[7] P3 International, "P4400 kill a watt operation manual," 2013.

[8] International Energy Agency, "World energy outlook," 2013.

[9] A. Carvallo and J. Copper, "The advanced smart grid-edge power driving sustainability," 2011.

[10] Smarthome New Product Catalog. Essential info for electrical detector. [Online]. Available: http://www.smarthome.com/9034/P3-International-P4400-Kill-A-Wat t-Energy-Meter/p.aspx

[11] J. Rosenow and N. Eyre, "The green deal and the energy company obligation," in Proc. the ICE-Energy, 2013, pp. 127-136.

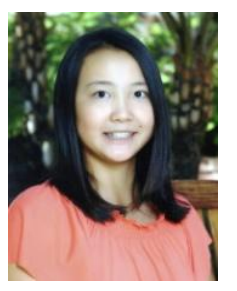

Angela Liu is a high school student at Polytechnic School in Pasadena, U.S.A. She lives most of her live in San Marino, California, U.S.A.

She loves science, math, and technology. Other than research in the residential energy management, she is working on optimal traffic light algorithm and self-learning residential thermostat algorithm.

Ms. Angela Liu is the founder and president of a non-profit organization "Blind Light Foundation" which helps visually impaired youths enhance their quality of life. Angela also received a President Obama's Volunteer Service Gold Award at the age of 14. She loves music and was the first place winner of the Cypress College Piano Competition, SYMF Open Ensemble and also the First Place Winner of SYMF flute Open American and Open Baroque. She loves golf. She earned San Gabriel Country Club Junior girl Golf Championships in 2010, 2012, and 2013. She is a team member of San Gabriel Country Club junior team which won 2012 Junior Metro League championship. She is also a member of Polytechnic Girls Golf Varsity Team. As a freshman, she was unanimously voted to the 2013 girl varsity golf MVP (most valuable player) award. 